Article

\title{
Turning Traditional Wisdom of Culture around: Making a Possible Transition to a Wiser World Driven by Culture of Wisdom Inquiry Real
}

\author{
Giridhari Lal Pandit 1,2,3,4,5
}

1 Department of Philosophy, University of Delhi South Campus, New Delhi 110021, India; panditgl@yahoo.co.in

2 Institut fuer Philosophie, Freie Universitaet Berlin, 14195 Berlin, Germany

3 Institut fuer Theoretische Physik, Fakultaet Physik und Astronomie, Universitaet Heidelberg, 69117 Heidelberg, Germany

4 Institute for Social and Economic Change, Centre for Ecological Economics and Natural Resources, Bangalore 560072, India

5 International Ernst Cassirer-Gesellschaft, Philosophisches Seminar der Universität Hamburg, 22297 Hamburg, Germany

Citation: Pandit, G.L. Turning Traditional Wisdom of Culture around: Making a Possible Transition to a Wiser World Driven by Culture of Wisdom Inquiry Real. Philosophies 2021, 6, 90. https://doi.org/10.3390/ philosophies6040090

Academic Editors: Nicholas Maxwell and Marcin J. Schroeder

Received: 20 May 2021

Accepted: 13 October 2021

Published: 22 October 2021

Publisher's Note: MDPI stays neutral with regard to jurisdictional claims in published maps and institutional affiliations.

\section{Copyright: (c) 2021 by the author.} Licensee MDPI, Basel, Switzerland. This article is an open access article distributed under the terms and conditions of the Creative Commons Attribution (CC BY) license (https:// creativecommons.org/licenses/by/ $4.0 /)$.

\begin{abstract}
In this article I discuss the problem of how we can change our world into a wiser world that is driven by a culture of wisdom inquiry (CWI), i.e., a world that frees humanity from a looming totalitarian catastrophe. How best can we interrogate the traditional wisdom of culture (TWC) that is responsible for the academic institutions of learning, among other kinds of institutions, dogmatically and solely aiming at the acquisition of knowledge and technological prowess (technologisches koennen), instead of the promotion of wisdom and human well-being? What kind of strategic transformations of institutional design, policy and goals within diverse institutions, particularly academic institutions of learning, regionally and globally, are imperative? This article argues from the principle of universal interconnectedness across nature/universe and the fundamental asymmetry of human well-being interests and nature's well-being interests. From this, the development of a culture of wisdom inquiry as an overarching (allumfassend) methodology of institutional change from within at two levels of analysis is proposed, viz., (1) at the level of the ecological-economic analysis of safeguarding nature's abundant ecosystems from human greed; and (2) at the level of the transformation of the educational, academic and political-economic institutions, as well as international institutions, that must be dedicated to human well-being.
\end{abstract}

Keywords: CWI (culture of wisdom inquiry); Wis-Design (wisdom-in-design); MWISc (methodology of wis-design-improvement science); BEREN correlations (biodiversity, ecosystem resilience and environmental-nesting correlations); anthropogenic evils (maux anthropiques, anthropogene Übel); BAUM-driven market institutions (business-as-usual model-driven market institutions); ETS progress (economic, technological and scientific progress); ADNE (accelerated domestication of nature's ecosystems)

"It appears to me that in Ethics, as in all other philosophical studies, the difficulties and disagreements, of which its history is full, are mainly due to a very simple cause: namely to the attempt to answer questions, without first discovering precisely what questions it is which you desire to answer." [1] (Preface vii)

\section{Introduction: Interrogating the Traditional Wisdom of Culture (TWC)}

Toward what should the academic institutions of learning aim at, particularly in the most challenging times when they themselves fail to function normally and deliver results? Should the academic institutions of learning, among other institutions, endlessly aim at the 
acquisition of knowledge and technological prowess so that the tomorrow's world will turn out to be smarter than today's world? Considering the fact that the world, which is loaded with deadly nuclear weapons, is also confronted with the evils of climate change emergency (CCE) and the coronavirus pandemic of 2020 (CVP 2020), the answer to our question is negative. First, despite economic, technological and scientific progress (ETS progress), these institutions have failed to solve the problems of living and human well-being across the different regions of the world. Anthropogenic crises such as global warming-driven climate change provide direct evidence for this. Second, before it is too late for humanity's survival, we must pause and interrogate the scale of these institutions' failures that are nowhere more visible than in the past 20 months of the devastating CVP 2020 [2-6]. It is clearly visible in our struggle to know the origin of the coronavirus pandemic and in our resolve to continue to fight this evil. Third, as and when we address this task, we must not fail to ask what has gone wrong with our diverse institutions including the academic institutions of learning and experimental labs such as the Gain-of-Function Virology Institutes [7-12]. We must seriously rethink what these institutions should aim for. Which universal ethical regulations and safeguards must they be subjected to? What is equally important, what is it that they should or should not promote? If I do not discuss these urgent issues here in great detail, it is only because of the limitations of space.

Nicholas Maxwell has quite convincingly argued for the view that the academic institutions of learning are in urgent need of a revolution [13-25]. Instead of aiming at the acquisition of knowledge they should dedicate themselves to promoting wisdom to help humanity to solve problems of living and well-being in the best way possible. In his own words:

"Much has changed since my book From Knowledge to Wisdom first appeared in the Orwellian year of 1984," writes Maxwell, "but we are as far away as ever from putting wisdom-inquiry into academic practice. As I see it, there is hardly any more important task confronting us, as far as the long-term interests of humanity are concerned, than to bring about the revolution in aims and methods of our institutions of learning, so that the basic aim becomes to promote wisdom." [26]

There is no doubt about the importance and urgency of bringing about such an institutional revolution. The question arises why no such institution-shaking revolution has taken place yet. How long can the philosophical discourses urging humanity to transform our institutions of learning be expected to remain unheeded or without benign impact? I want to turn to this important question in a future publication. I have appraised in considerable detail Maxwell's aim-oriented empiricism and aim-oriented rationalism, and his conception of wisdom inquiry [27-37].

I have myself presented arguments in support of Maxwell's normative methodology, offering and articulating independent grounds why wisdom inquiry must be a top priority $[28,31,32]$. If the institutions devoted to solving the problems of living and human well-being fail, particularly in times of crises, it is of crucial importance to diagnose their failure for the purposes of redesigning these institutions, for much will depend on how the existing institutions themselves are designed. The present article focuses mainly on the academic institutions of learning among other types of institutions across the world, including the international institutions. The question it seeks to address may be formulated as follows:

How might these institutions wisely function, contributing to human well-being, within a new framework of a culture of wisdom inquiry (CWI)?

Normally academic institutions of learning are accustomed and supposed to work within the frameworks of knowledge inquiry and technology that have their deep roots in the traditional wisdom of culture (TWC). In summary, I propose to argue how urgent and important it is for these institutions to work within CWI, transforming themselves from within. In particular, regarding the academic institutions of learning and experimental laboratories of science, instead of aiming at the acquisition of knowledge and technology, 
they must work within CWI to promote wisdom by solving problems of living and human well-being, while rebuilding a wiser world.

From the very outset, a word of caution to the serious reader is in order as regards the nebulous concept of 'wisdom'. From an analytical philosophical perspective, this concept is a pre-systematic/pre-analytic normative concept rooted in the original resources of natural language. Natural languages themselves are a major tributary of TWC [38,39]. Thus, for reasons that will become clear as we proceed, the concept of 'wisdom' is a good example of those pre-systematic concepts that are better implicitly defined in the newly emerging problematic contexts. Such concepts are, if articulated, better replaced by systematic concepts in the particular problematic contexts. As early as 1903 G. E. Moore warned the students of ethics against naturalistic fallacy, a consequence that inevitably follows the attempts to define "good" / "goodness" in terms of some simple natural quality [1]. I think that one could extend Moore's insight to the concept of wisdom. Moreover, imagine if the concept of wisdom was easily definable in few simple steps. Assuming as if there was a broad consensus in its favour, we would start believing that we 'know' what wisdom is, i.e., which people with which qualities can be ranked as wise persons. And which people with which qualities could not be so ranked. Would not that amount to claiming that our human knowledge, whichever way defined, invariably covers 'wisdom'? Would that not amount to claiming that knowledge includes 'wisdom' as an object of knowledge in the same way in which qualities of 'honesty' 'friendliness', 'boldness', helpfulness', and 'saintliness' can be considered as objects of knowledge? The answer is yes because the implications of treating wisdom as an object of knowledge, among other such objects, would contradict the basic assumption that knowledge and wisdom do not belong to a single category. Knowledge inquiry and wisdom inquiry are quite distinct from each other. It is not only possible but urgent to bring about necessary institutional change in order to build a better and wiser world by prioritizing wisdom inquiry over knowledge inquiry.

In this very context, we must ask what is the locus of the kind of change that we ought to be aiming at? Clearly it lies in a whole diversity of institutions and their 'ecosystems' in which they are embedded. Would it not be beneficial to mankind to radically rethink/relearn wisdom so that the individuals and societies and organizations are more and more encouraged to search for wisdom in their institutions instead of themselves, i.e., instead of individual persons as the subjects of predication? I have no doubt in my mind that if any change is to take place outside us, i.e., within our institutions, our baby steps to relearn wisdom must start from here. We must relearn how and where to put wisdom within the institutions from the very beginning when they are designed and built. The concept of Wisdom-in-Design, one of our key-concepts, assumes here crucial importance [40].

To my critics it may appear as if, in saying this, it is my intention to deny that individuals in society may be more or less wise in varying contexts in the subjective sense of the term, both in their own and others' assessments, just as the concept of 'good' is applied in judging the character of individual human beings in different contexts. This is not my real intention. I have nothing against the view that wisdom is definable simply as a kind of quality that an individual human being may proudly claim to possess. Thus, in the inter-personal context, one may agree with Nicholas Maxwell when he defines "wisdom" explicitly as "the capacity, the active endeavour and the desire to realize what is of value in life, for oneself and others, wisdom in this sense including knowledge and technological know-how, but much else besides, while recognizing that what is of value is often deeply problematic" [13-25].

My point is rather quite different. In the context of institutional change, which is undoubtedly no less problematic than the inter-personal context, I think that wisdom is essentially a normative/value-laden nebulous concept. One may even rank it among the highest values of beauty and justice. Instead of rushing to define it reductively without first interrogating its traditional uses, if we articulate and develop the concept of wisdom objectively in the varying problem-solving institutional contexts, the resulting resourcefulness of the concept in question can increasingly serve us better. For example, it can serve 
us in interrogating and putting the institutions themselves on a path driven by wisdom inquiry. This kind of approach has important consequences, which I will discuss presently.

Thus, where the reader may expect a definition of wisdom, in the inter-personal context, my argument builds on the following five fundamental assumptions of how it might be better articulated systematically in varied problematic contexts of institutional change. An important first step in such articulation would be:

To attribute 'wisdom' to a delivery system within a natural system, say a natural ecosystem, or within an institutional/technological/organizational system/design, e.g., a university, provided that such systems/sub-systems are characterized by a capacity to reduce risks and stupidities in the riskiest of situations, environments and societies.

The same applies to the policies that are framed to shape state-building, education, research and development, and to handle global challenges before humanity. The task of wisdom inquiry should be to explore this frontier of wisdom so that the societies, universities, technologies, industries, cultures can better cope with risks and stupidities. In a nutshell, the advantage of wisdom in the university or a research lab, considered as a delivery system, is its capacity to guide knowledge resources dynamics [28] in order to reduce looming risks, stupidities and negative externalities.

Thus, while knowledge and technological prowess may be easily definable concepts, wisdom, a value-laden concept, is not so easily susceptible to definition, particularly in the context of institutional change. The kind of transformation that is needed for all institutions, regionally and globally, notably the academic institutions of learning, can best take off by transitioning from TWC to CWI by the wide-ranging institutionalization of wisdom inquiry. This has the following deeper implication. In any serious analytical-philosophical discourse on wisdom, it is inevitable to move away from the pre-systematic/pre-analytic uses of the term "wisdom" to its highly systematic use in precisely specified problematic contexts such as the global challenges that this article seeks to articulate. Think of the following challenge:

In the present global situation, if we worry about the future of humanity, culture, education, academic institutions of learning, scientific laboratories, healthcare systems, and other regional and international institutions such as the UNO and $\mathrm{WHO}$, will the smartness of our present civilization and TWC be enough to meet the present and future global challenges? Will they be enough to improve the global scenario without our desperately clinging to business-as-usual ad hoc strategies and quick-fix solutions?

The answer to these questions is clearly in the negative.

Second, it is generally accepted that culture is not the same thing as civilization. For example, the latter covers technological advances in warfare such as the nuclear weapons, atomic and hydrogen bombs, robotics and other automatized industrial goods and services, artificial intelligence, and so on. Unlike civilization, culture or cultural dynamics cover all human activities, universal human values, institutions, traditions, architectural designs, education, research and the pursuit of knowledge, fine arts, languages, music and so on. Thus, culture alone offers the template for the pursuit of the higher values of wisdom and moral progress for human well-being that humankind can dream of. In this latter dynamic aspect, TWC appears as a higher value in its own right, a higher value of learnability and sustainability of all that is embodied in the best of the institutions and traditions created by humans. Yet, TWC would not be enough to meet the current and new global challenges.

This leads to the third assumption this article makes regarding the development and implementation of CWI as an overarching discipline. CWI can play a crucial role not only in transforming the academic institutions of learning, their aims and functions, but also in judging and ranking them, among other institutions, in terms of institutional Wisdom-in-Design, which helps most strategically to solve problems of living and human well-being. 
Fourth, there is an intimate relationship between the institutions of learning and all other institutions, regional and global, so that no revolution in the academic institutions of learning can be completed without a revolution elsewhere, e.g., in institutions of the political economy of the environment, or in those of medical research and healthcare. If we assume that academic institutions of learning, including schools, colleges, universities and research laboratories, are no less 'ecosystems' in their own right than the forests and lakes that are defined by ecologists as 'biological communities of interacting organisms and their physical environments', the implication for our understanding and designing of such institutions become far-reaching. Not only will it improve how we internalize ourselves into their structure, it will also improve how we set their aims and objectives rationally and wisely. When viewed as 'ecosystems', institutions of learning are best understood as being embedded in the larger 'ecosystems,' Thus, they function and deliver their services within the larger 'ecosystems' comprising of all other institutions, including international institutions.

The fifth and the last assumption addresses the unasked question of what the humanfreedom-and-human-dignity enhancing institutional wis-design should be so that it can work against the looming dangers of totalitarianism. Such dangers permanently loom over humanity at every step of knowledge inquiry driven by the ETS progress. Sadly enough, during the past 20 months of the coronavirus pandemic, we have witnessed dictatorships and bureaucracies rising and thriving across the world. We have witnessed the extent to which they have diminished human dignity and freedom on our finite planet earth [41]. If this is not institutional failure at the local, regional and international levels, then what is? Keeping this in view, the fifth assumption may be tentatively formulated as follows. The prospects of wisdom inquiry-driven institutions at the regional and international levels taking over the existing institutions would be the best guarantee against totalitarianism in any form and disguise. For the purposes of promoting the values of fundamental human rights, enhancing human freedom and dignity, safeguarding open society, transparency, accountability, moral responsibility, and moral progress in promoting harmonious human and non-human well-being, the newly proposed and the newly structured/designed institutions must be driven by the human-dignity-and-human freedom-enhancing culture of wisdom inquiry $[41,42]$.

The title of this article poses the following question: How might a CWI-driven transition to a new world be realized? Depending on the answer, how best can we free our post-CVP 2020 world [2-6] from the baggage of anthropogenic evils that we have inherited from our past civilizations? How can we turn our past history into our best teacher? In particular, how can we free ourselves from a dogmatic faith in the pursuit of science and technology as if these are humanity's ultimate saviors? We must never ignore the threat of the virus of terrorism across the globe that has been so destructive to the world of human values; notice how smartly terrorism employs the same technologies that are celebrated so proudly as collective human achievement by one and all [31]. We may continue to depend on science and technology in all kinds of ways in all fields of problem-solving human activity, particularly where being smart matters more than being wise. However, sooner or later we have to develop ways and means that can free us from all forms of dogmatism, including the dogmatism of blind faith in science and technology [43]. More importantly, we must not hesitate in guarding humanity against the technological totalitarianism that our civilization celebrates as if it is the ultimate savior [31]. Thus, the most important of all lessons that can be learnt from recent and past human history is how mankind might transition from TWC to CWI so that humanity may build a better and wiser world in terms of better institutions. Such a world can be driven by the methodology of wisdom inquiry that I would like tentatively to designate as the methodology of wis-design-improvement science (MWISc). The newly introduced concept of wis-design (Wisdom-in-Design) is again better implicitly defined so as to allow its meaning to evolve in the appropriate contexts of the implementation of diverse overarching centers of study that aim at promoting wisdom and human well-being. The implementation of wisdom inquiry in an institution such as a 
school, college, or university entails establishment of new centers of study that can situate wise policies and decisions within each department/faculty in the solutions to problems of living and human well-being.

Hence, I am here mainly concerned with institutional design and change. More precisely, my article is concerned with the question how best we can determine how much wis-design an institution requires to deliver the services it intends to deliver, on the one hand, and to achieve the aims it is expected to achieve, on the other hand. Obviously, this task goes far beyond the practice of institutional ranking that usually operates according to the pre-conceived notions of how to judge the excellence of an institution, among similar institutions.

Building on the important distinction I have drawn between TWC and CWI, the following Sections 2-5 address the greatest challenge of how to redesign diverse institutions, notably academic institutions of learning, as well as the international institutions where these are dedicated to human well-being. I would like to include in these institutions the scientific experimental laboratories and institutes of healthcare, particularly the Gain-of-Function Virology Research Institutes [7-12]. The question is, first of all: how can we best implement wisdom inquiry within these institutions and within regional and international institutions? Secondly, which basic principles and policies of development of CWI, as distinct from the traditional wisdom of culture, can be adopted so that the basic aim of the institutions of leaning and international institutions becomes the promotion of wisdom and well-being of individuals and societies across the world?

Drawing attention to the ecological economics of nature's ecosystems that are rich in ecological complexities, dynamics, resilience and nature's wonderful designs $[27,28,32,43,44]$, Section 2 briefly discusses environmental nesting model of ecological-environmental realism (henceforth environmental realism). Environmental realism addresses the issues of nature policy to reduce the anthropogenic evils of the accelerated domestication of nature's ecosystems (ADNE). The pursuit of GDP-driven economic prosperity exclusively in the interest of human welfare often lands us in negative externalities such as global warming and climate change crisis (CCC). Environmental realism seeks to correct and change the driving forces behind this scenario. It discusses the issues of how to safeguard the natural world against destructive human activity and how to shape and return to a robust nature policy. My technical discussion of the asymmetry between human well-being interests and nature's well-being interests warrants a consideration of nature policy as a key to human well-being. In summary, there can be no rigorous discussion of human well-being interests without first discussing nature's well-being interests, and not vice versa.

Section 3 articulates and interrogates TWC briefly with reference to the Greek philosophical tradition, Sanskrit literary tradition and the celebrated University of Visva-Bharati, designed and founded by the poet-seer, Nobel Laureate Rabindranath Tagore, in West Bengal, in 1921 [45]. It then discusses the question of how the academic institutions of learning, among other institutions, can cope with the global challenges by transitioning from TWC to CWI by taking steps towards the institutionalization of wisdom inquiry. At this point, the concepts of universal interconnectedness and Wisdom-in-Design emerge as key-concepts preparatory to the institutionalization of CWI.

Section 4 draws attention to two issues closely related to the main theme of the article. The first issue relates to the illusions of the business-as-usual model driven (BAUM driven) innovation that businesses and market institutions ritualistically promote. The second issue relates to the urgently needed redesigning of the delivery systems in academic and other institutions. Here, my argument develops as follows:

In a post-CVP 2020 world [2-6] every generation should be morally obliged to ask scrutinizing questions addressed to the institutions of education and learning, notably the following question: With each generation of educated young men and women that step out from the academic institutions of higher education, how much wiser, not how much smarter, will the world become? A wiser world 
in this context is a step in moral progress that humankind can make over and above ETS progress. [42,43]

Section 5, the Epilogue, summarizes the preceding discussions of Sections 1-4.

\section{Environmental Realism: The Asymmetry of Human Well-Being Interests and Nature's Well-Being Interests}

With a view to serving nature's well-being interests as wisely as possible, the environmental nesting model of environmental realism is crucial to the shaping and reshaping of nature policy, regionally and globally $[27,28,43]$. As a strategy of habitation used by diverse species within nature's ecosystems, environmental nesting leaves ecological economists wondering how the enormous complexities, underlying the ever-growing ecosystem resilience, are so perfectly handled by nature [27,28,43,46]. However, the biggest difficulty encountered in this context is as follows. We humans know too little about the biodiversity $\rightarrow$ ecosystem-resilience $\rightarrow$ environmental nesting correlations (BEREN correlations) that are obtained in nature. BEREN correlations involve complex dynamic processes which cannot be easily reproduced in the experimental laboratory artificially. Outside nature's ecosystems on land or in the oceans, it is very difficult to reproduce them. As a key idea, BEREN correlations could help scientists, nature lovers, academics, planners, economic policy makers and institution builders in many ways. They could provide them with the keys necessary to understand rural resilience/ecosystem resilience while we relentlessly address the following global tasks with urgency:

1. Characterizing the relationship of dependence of the rural and coastal communities on their local natural resources and ecosystem services;

2. Understanding how dynamic interactions and nested dependencies develop among the diverse species that constitute the sub-soil ecosystems;

3. Designing and redesigning of nature policy of how best we may re-connect ourselves with nature, particularly the policy of working with and not against nature, given that the ecology of our consciousness itself builds upon the dynamics of humankind $\rightarrow$ nature and part $\rightarrow$ whole relations $[27,28,42-44]$;

4. Promoting a policy of an ecological economics-based approach for the issues of sustainable development [UNSDGs 2030], [27,28,30,31,40,47];

5. Developing alternatives to the accelerated domestication of nature's ecosystems (ADNE) by humans. ADNE is a misguided policy of overexploiting and controlling nature's resources exclusively for human uses and benefits. Such a policy amounts to the unsustainable policy of working against nature's well-being interests [46].

As an example of ADNE, think of urbanization and the loss of forest cover of Earth. Urbanization represents the human urge to over-domesticate nature by ADNE, in the exclusive pursuit of narrowly conceived GDP-driven economics of prosperity and growth [42]. However, how wise is it for mankind to urbanize and over-domesticate nature, exclusively pursuing human economic interests of well-being and development? On the contrary, for planned urban life, sustainable cities, rural well-being it is imperative to have a healthy nature policy, based on the ecological economics of the BEREN correlations. Since the 1960s, Earth has a decreased forest cover by about $1 \mathrm{~m} \mathrm{sq} \mathrm{km}$ while cropland and pasture areas have increased, thanks to ADNE-driven policies of economic development. We must try to know how, as a consequence, the negative externalities such as climate change set in due to global warming, adversely impacting human well-being.

Think of ecosystem resilience. It refers to those properties within nature's ecosystems that determine the structural and functional stability of ecosystem services in the presence of external disturbances, disruptions or perturbations. It does not exhaust all the complexity residing inside the ecosystems, nor their full dynamics. The concept of environmental nesting may, on the other hand, help us at this point, since it refers to dynamic interactions and nested dependencies developing among species that constitute these ecosystems [30,32,43,46,47]. 
I believe that nature and biological evolution have from time to time taught us humans a variety of lessons in 'wisdom'. In the context of human societies and political economies we may designate these lessons as wisdom of culture, i.e., wisdom that culture bestows on men and women through their work, lifestyle, family life, education, tradition, their use of language and reason, by way of a kind of feedback from culture once it is itself living out there. Thus, different cultures have taught us that in situations of conflict and war it is not necessary to fight bloody wars by killing the enemy forces on the battlefield in cold blood. The best of these cultures even teach us more valuable lessons. For example, science teaches us that in scientific revolutions it is our theories that can die in our stead [48-53]. This is exactly what humankind learns from the rationality of the methodology of science $[49,50,54]$. Today it is imperative that humanity moves forward from the traditional wisdom of culture in order to develop a culture of wisdom inquiry. As a matter of policy with regard to nature's ecosystems, education and academic institutions of learning, it is imperative to launch the following inquiry [31,35-37]:

In order for nature's ecosystems on land and in the oceans to keep sustaining Earth's wonderful biodiverse world including us humans and the treasures of our traditional wisdom of culture, which basic principles are necessary to develop a culture of wisdom inquiry that can be of strategic help in sustaining all of them, i.e., nature's ecosystems themselves, as well as our traditions, cultures and academic institutions of learning? [42]

For fostering sustainable life and sustainable development regionally and globally, it is necessary to regulate ADNE (UNSDGs 2030). However, this is not possible without creating a proper regulative order over human-nature interactions, in terms of BEREN correlations within environmental realism. As I have indicated above, in its conceptual framework, environmental realism/Umweltrealismus $[27,43,44]$ is rooted in the twin concepts of (i) environmental nesting chains and dynamics that define the dynamic web of life across nature's ecosystems and (ii) environmental nesting strategies that contribute to our ability to shape a healthy nature policy and to lay down the imperatives of sustainable life and sustainable development [27-32,42-44,47,55-58].

In summary, environmental realism is about an asymmetry between nature's ecosystems and us, i.e., the top species, on the one hand, and universal interconnectedness across nature/universe, on the other. The former, i.e., the asymmetry, can be ignored only at our own peril. Therefore, the very existence and survival of humans, along with the invented environments in which most modern societies live on Earth, are not necessary for the continued existence of planet Earth, other things remaining the same. However, on the other hand, a continued survival of humanity without the life support of Earth's ecosystems is totally inconceivable. Hence, there is an asymmetrical relationship between man and nature, i.e., between culture and nature, which cannot be broken. More importantly, this asymmetry has consequences for our nature policy that cannot be ignored: Humanity's dependence on nature is total; while nature's independence from man is quite evident. Of course, the same may hold true regarding the other forms of life on Earth. This principle of asymmetry can be very generally formulated relative to all forms of existence on Earth as follows:

Wherever these forms of existence are governed by the structure-property corre-

lated part-whole relationships, the whole is conceivable without the part but not the part without the whole. [42,43,55-58]

From this asymmetry, we can draw the following lesson for developing a sound and strategic nature policy that should regulate and govern human-nature interactions. $\mathrm{Hu}-$ manity ought to foster studies in terrestrial ethics as a framework for a better understanding of nature's well-being interests, where nature is considered a whole of which humans are just a tiny part. This is imperative, if only for a better understanding and appreciation of the human interests of well-being [59] (pp. 241-242). 
For nature's ecosystems on land and in the oceans to keep sustaining Earth's wonderful biodiversity including us humans along with our treasures of TWC, the wide-ranging institutionalization of wisdom inquiry is imperative. Only CWI can be of strategic help in shaping our nature policy in order to sustain nature's ecosystems, on the one hand, and our traditions, cultures, academic institutions of learning and international institutions that are dedicated to human well-being, on the other hand.

To conclude, environmental realism provides the key to a healthy nature policy. The ecosystems of the oceans and of the Earth as a whole, which host life in all its biodiversity, are in great ecological distress, thanks to the accelerated ETS progress [27,28,32,43,59]. Have we ever cared enough for their health and resilience? Have we ever thought of their vulnerability to the adverse environmental impacts of our own irresponsible actions that are aimed toward ETS progress? Without their resilience, our planet could not host life in all its biodiversity. Nor could the humans breathe and engage in scientific and economic activity. Insofar as the schoolchildren and college students have a possibility to learn lessons in ecological economics of taking care of nature's ecosystems and of Earth's biodiversity, it would be instructive to research how this impacts their quality of life. To put it very generally and simply, the more we care about nature's ecosystems, the more they take care of the quality of our own life and that of Earth's biodiversity. Today, it is no longer a secret that our planet and its oceans are threatened by the negative externality of CCE due to all human activities that aim at ETS progress. Humanity's biggest failure lies then in its institutional failure. We have never properly thought of how the political economy of the environment, regionally and globally, along with a healthy nature policy could be so realistically designed as to prevent the negative externalities from arising recurrently. I am here referring to the negative externalities of global CCE, on the one hand, and the "Great Pacific Garbage Patch", an estimated 80,000 metric tons of plastic occupying the patch, on the other [31].

\section{Institutions of Learning in Urgent Need of a Culture of Wisdom Inquiry}

Imagine what kind of educational institutions prevailed in India one hundred years ago under the British Empire. Boldly answering his own question as to what should be the ideal of education in India, the poet-seer, Nobel Laureate Rabindranath Tagore [45], who founded India's celebrated university, Visva-Bharati, in Bengal, in 1921, wrote prophetically and philosophically as follows:

"On each race is the duty laid to keep its own lamp of mind as its part in the illumination of the world. To break the lamp of any people is to deprive it of its rightful place in the world festival. He who has no light is unfortunate enough, but utterly miserable is he who, having it, has been deprived of it, or has forgotten all about it." [43,45] (p. 1)

Tagore was referring to Indian culture, as one of the cultures of the world. More specifically, in this very context, Tagore reminded the world that "The main river of Indian culture has flowed in four streams - the Vedic, the Puranic, the Buddhist, and the Jain [60,61]. It had its source in the heights of the Indian consciousness [45] (p. 34)." The Visva-Bharati of Tagore's imagination was to be designed by him as a university where the whole world, i.e., humanity with a wisdom of culture, would make its choicest nest $[40,45,60,61]$. Even when viewed narrowly as a center of Indian culture, Tagore thought it imperative that it "should not only be a center of the intellectual life of India, but the center of her economic life also", citing the example of Tapovanas, i.e., the ancient Indian schools and universities that had their campuses embedded in nature's wonderful forests [45] (p. 41). Thus, Visva-Bharati would set the example as an institution of learning that would integrate around itself,

" ... all the neighboring villages and virtually unite them with itself in all its economic endeavours. ( . . . ) In a word, it should never be like a meteor-only a stray fragment of a world-but a complete world in itself, self-sustaining, independent, rich with ever-renewing life, radiating light across space and time, 
attracting and maintaining round it a planetary system of dependent bodies, imparting life-breath to the complete man, who is intellectual as well as economic, bound by social bonds and aspiring towards spiritual freedom." [45] (pp. 41-42)

To this day, despite the changes it has undergone over time, Visva-Bharati remains embedded in a rural setting comprising of the surrounding ecosystems, biodiversities, villages, farm lands and cottage industries.

It is important to remember that Visva-Bharati was born as the centre of learning "where the world makes its home in a single nest" (in Sanskrit: "Yatra Visvam Bhavatyekanidam"), as the poet-seer Tagore himself had designed and inscribed the motto on its institutions $[40,45]$. However, how is it possible to conceive of the nest, i.e., the Oekos, as well as the habitat, the ecosystem, the institution, the university, the host planet Earth, and so on as a world? With Santiniketan in West Bengal as its campus, this question lies at the very foundations of Visva-Bharati which the poet-seer Rabindranath Tagore had conceived of, in December 1918, and founded three years later, in December 1921. On the model of the forest-schools (Tapovanas) or forest-homes of ancient India, Visva-Bharati evolved from an experimental school which the poet had developed as early as December 1901 from the Santiniketan Asrama that the poet's father, Maharishi Devendranath Tagore, had founded in 1863.

In this context, we may be reminded of environmental realism which teaches us how crucial it is to relate ourselves as ecological selves, along with our habitat or our nest, with the environmental nest of universal interconnectedness [27,28,30,32,40,43,44,55-57]. Environmental realism entails a dynamic movement back and forth, from our habitat to the environmental nest and from the latter back to the former. From the two ideas of the world as a nest and the nest as a world, it should be possible to build an environmental worldview that allows a dynamic movement back and forth between these two kinds of worlds. The dynamic process, by means of which we can relate ourselves to the environmental nest of universal interconnectedness, potentially regulating our local actions and minimizing their destructive, domesticating, environmental impact/footprint, may be simply called the environmental nesting model of environmental realism [27,30,43,44,55-58].

No culture can survive without its traditions, just as no religion can survive without its rituals. It has been said that "the cultural landmarks can change the fortunes of decadent cities." The need to revisit the question of what wisdom of culture is, and what it is not, may be more urgent now than it ever has been. The world that the top species has so smartly built up over many past millennia is shaking now in the fight against the CVP 2020 [2-6]. While it is shaking, is it also waking up from a dogmatic slumber and learning a lesson from the remembered past? We must try to understand why the task of understanding wisdom of culture is urgent. Consider how difficult it is to properly formulate problems of human living and well-being in the post-CVP 2020 world [2-6]. How and where can we begin? Where can we find a proper orientation if we have to first identify the advantageous, conceptual resources to address these very pressing problems? One may have to contend with undertaking a long conceptual journey through a conceptual maze of methodological questions and definitions. Therefore, I am not going to risk any workable definition of what wisdom of culture is. Yet, we may speak of 'wisdom' in the analogous, realistic, empirical sense of abundant resources of the design, resilience, functionality and efficient delivery systems we find across and within nature's ecosystems. 'Wisdom', if analogously understood in this sense, may be called Wisdom-in-Design or simply Wis-Design [40]. The resilience of nature's ecosystems alone teaches us a lot about the kind of Wis-Design that can sustain them structurally and dynamically under varied climatic conditions, and more so in times of climatic crises that may be natural or anthropogenic. Evidently, the key to their resilience, and therefore to their Wis-Design, lies in biodiversity. So, we may ask the following question: If the biodiversity built into nature's ecosystems is not a matter of Wis-Design, then what else is? In close interaction with nature, it is in nature's Wis-Design that we, the top species, can find the best teacher of what systemic wisdom is. This raises the question: 
How can we learn lessons from nature's Wis-Design to a sufficient extent to transcend the wisdom of culture and then transition to a world driven by CWI?

This step is necessary if we may want to develop a detailed idea of Wisdom-in-Design and turn it around to transform it into a whole new CWI. How can we accomplish all this in order to fight those very regional and global challenges that humanity is currently confronted with, i.e., challenges that cannot be met merely in terms of TWC that proves highly vulnerable to technological totalitarianism [30,31,41]?

On the other hand, we should not be surprised if we find significant parallels to nature's Wis-Design in TWC. For example, if the Rig-Vedic aphorism "Vasudhaiva Kutumbakkam" (meaning "Earth is a joint family") is not wisdom of culture, then what is? It serves us as the best reminder of how humanity is deeply and intimately wedded to Earth as a joint family. More importantly, we must not fail to recognize how crucial the ecology of consciousness is to our individual and collective well-being, i.e., to our spiritual, psychological, biological, sociopolitical and moral well-being [30,43,60]. Simply put, planet Earth intimately shapes us from birth to death. Earth itself is the ecology of our consciousness and we, as individuals, are rooted in Earth [27,43,44]. In other words, the recognition of Earth as the ecology of our consciousness is crucial in any attempt to remake our world as more wise or more careful than it was before. Since World War II, it has never been so imperative in recent human history as it is now to remake our world as best and as wisely as we can.

If we go back in time and turn our attention to the TWC, enshrined in Greek mythology/philosophy and in classical Indian Sanskrit literature, we cannot miss the Socratic Dialogue/Dialectic as a cultural model of education and democracy [41,42,60]. Far from ceasing to be relevant, this model is crucial to promoting the values of culture, education, wisdom and human well-being, especially in our fight against anthropogenic evils, such as the CCE, CVP 2020 [2-6], totalitarianism and, above all, the abuse of religion for the promotion of terrorist violence against innocent victims. All of these are the biggest current challenges confronting humanity. However, one might wonder how we can solve the problems of living and well-being on a finite planet that is itself endangered by these very anthropogenic evils. Does the answering of these questions, therefore, require us to take a closer and unbiased look at the delivery systems of academic and other kinds of cultural/political-economic institutions in order to prepare for instituting CWI? Yes, we must address our questions not only to schools, colleges, universities, IHRs (e.g., International Health Regulations, 2005), and GOFVRIs that conduct G-O-F experiments [7-12], but also to ecological economics of nature policy, healthcare systems, human rights institutions, international institutions such as the UNO and WHO, whole industries and their production of goods and services and management of business supply chains, among others [42].

\section{Do Businesses Create Their Own Educational Platforms? Against the Ad Hoc Digitalization of Institutions of Learning}

How do businesses and organizations ensure a tradition of recruiting new employees, while creating an amazing employee experience to retain and develop existing human resources? The major challenges to job creation call for a critical approach to technological prowess instead of a blind faith in it $[41,42]$ What does one do if advances in technology replace one's role in a job for which one was competent and qualified before the new technology arrived in the name of innovation? In such a situation, it would appear as if the education and knowledge that you acquired at the institutes of learning no longer qualify you for the same job because new technology now disruptively interfaces with the job market replacing human workers. Consider an altogether different scenario: if technologies of $\mathrm{AI}$ enter everywhere in the name of innovation, what will happen to the job market for the younger generations and the most disadvantaged among them? It is least helpful for critical thinking to turn to Japan as a country desperately turning to such technologies simply because Japan lacks sufficient manpower/human resources to fill the job market 
locally/regionally, not because of 'unqualified' job seekers; there being no job seekers at all. Should the recourse to technologies of AI become a worldwide fashion, India's younger generation will suffer from rampant unemployment. Moreover, the younger a country is, as regards its population, the worst the consequences are [41,42].

A most tricky question that is easy to ask but difficult to answer in the context of modern technologies may be posed as follows: Do the business models and technological solutions being innovated by the enterprises regionally and across the globe really create their own educational platforms? Because technologies are rapidly developing and new professions are emerging, one cannot continue to work without learning new skills. Because new technologies bring in creative destruction that renders older skills and skilled workers irrelevant and the learning of new skills necessary, are we to take these processes of dislodgement (Vertreibung) for granted? Are we to accept the dislodgement of employees as an inevitable consequence of new technologies taking over at an alarmingly great speed? On the contrary, should we not feel obliged to step back and interrogate these processes [41,42]? Are we not obliged to properly interrogate these technologies and the people responsible for them? Are we not avoiding accountability issues if we dogmatically declare a large number of employees as "uneducated-unskilled" simply as a consequence of dogmatically embracing the new technologies being deployed [41,42]?

From a moral perspective, are there universal ethical principles of intervention with which one may judge the real moral worth of these processes of innovation themselves, their results as well as their future impacts? This question should serve to remind humanity of the powerful money-making technology companies in which the world is simultaneously deeply and shallowly drowning. Leaving the issues of the Internet aside, I am here referring to notable examples: Twitter and Facebook, among so many so-called 'social media' portals. I think that these technology companies are the best examples of how the rapidly developing technology, in their case the Internet, creates the illusion of innovation looming on the horizon, on the one hand, while also creating the perversely damaging illusion of businesses creating their own educational platforms, on the other hand. Even if the present world is mostly driven by these multinational technology companies, it is our obligation to ask how unregulated and unruly these companies are. Why being unregulated and unruly does not prevent them from zealously seeking to expand their businesses by ruling and dominating over our daily lives and activities? They do this to such an extent that we all, the end-users, feel constrained to let them frame the regulations including the 'rules' that are allegedly meant to protect our individual and collective privacy $[31,41,62]$.

I think that the real challenge lies elsewhere. In a post-CVP 2020 world [2-6], every generation of educated men and women would be morally obliged to ask scrutinizing questions addressed to the institutions of education and learning, among the other institutions. One of these questions is as follows: With each generation of educated young men and women stepping out from academic institutions of higher education, how wiser, not how smarter, has the world become, a wiser world being a world where moral progress and human well-being over ETS progress matter most?

Would it be a surprise, if the world's institutions of learning, as we knew them before the global outbreak of CVP 2020 [2-6], do not pass this test? Yet, there is a lot that we may learn from putting them to a crucial test. In particular, what we should look for is how the international institutions, e.g., the $\mathrm{UNO}$ and $\mathrm{WHO}$ and their agencies, have failed to deliver the services they were supposed to deliver, particularly in times of global need and crisis. Similarly, we can subject the regional and local institutions, including the academic institutions, e.g., schools, colleges and universities, to a crucial test. We would not be shocked to find how these too have failed to deliver the services they were supposed to deliver in both normal and exceptional circumstances [31]. From time to time, the TWCdriven institutions, such as the academic institutions of learning, have been oriented to make our world increasingly smarter and safer. Yet, our world has increasingly moved away from this goal, increasingly becoming unsafe and riskier. 
Destroyed by the anthropogenic evils such as CCE and CVP 2020 [2-6], as our world has been, some of the initiatives for the purpose of envisioning and re-building of our world, i.e., a post-CVP 2020 world, may be already in the pipeline, if not ready for implementation. The world leaders in science, medicine, and politics, as well as regional experts and policy planners are already searching for technological designs for piecemeal repairs, as well as possible major replacements to bring in functional and structural reforms in the institutions. Efforts are being made to offer smart solutions in order to continue digital conferences and debates on important themes and issues. How such smart business solutions can rescue human beings and societies in times of global crises has been, undoubtedly, put to the test, particularly for the past 20 months. On the other hand, how the TWC-driven, smart initiatives of different countries are locally shaping diverse responses to CCE and CVP 2020 [2-6] can hardly be missed. In this global scenario, notice how the European Union member countries undergoing measures of lockdowns are struggling to keep schools open for classes for the benefit of schoolchildren while others have seen the implementation of stricter measures to control the CVP 2020 [2-6]. In the South Asian countries such as India, on the other hand, schools have still not opened since March 2020 when the CVP 2020 was first announced by the CCP in Wuhan, China [2-6]. In the name of "education made easy", the children are challenged to study at home online. In many cities across the world, parents and teachers keep pondering over the most important question:

What is more important for the future of culture? Are not the institutions of family, of education, learning and democracy more important? Are not the safety of the school children and their education according to the classical model of mindful and rigorous dialogue with the teacher in the challenging yet harmonious environment of the classroom more important? Where else can the values that go together with education be best inculcated in children, if not in the knowledge environments of their schools?

TWC, already stressful and yet challenged, is clearly at work here. In final analysis, the seemingly attractive digital technology, offering 'short-cuts to schooling' and 'schooling made easy,' may not be so attractive and beneficial after all, either to children or to society itself. At best, it will serve as a solution within the BAUM-driven market institutions, resorting to readily/easily available solutions.

The coronavirus pandemic has accelerated and increased our dependence on digital world/technology, while decelerating and decreasing our cultural interactions. What a boost to technological totalitarianism! Arguably, the challenges posed by the CVP 2020 [2-6] cannot be met, and should not be met, by shifting the fundamental problems of institutions of learning to the portals of technological advances in digital learning and conferences [42]. On the contrary, these institutions themselves must be prepared for change. For example, the schools must lose no time for overhauling the structural design of school classrooms and the class sizes. Instead of having a large number of children in the same classroom, smaller classes must be designed as a result of what we have learnt from the CVP 2020 [2-6]. TWC, a value of values in its own right, transcends technology and its devices/tools of distraction and destruction. If the CVP 2020 [2-6] is used as an excuse to transition to the 'digital world,' it is not only unwarranted but misguided [42]. No transitional ad hoc solutions can be considered as permanent well-thought-out solutions, except within the BAUM-driven market institutions. What is worse, there will be a lost generation, those who do not cope well with these kinds of ad hoc media. It is imperative to get back to "real teaching" in the proper knowledge environments of schools, so that all children have access to equal opportunities.

All the academic institutions and think tanks across the world are currently functioning far below their normal capacity, online, due to technological innovation and because of our unwavering dogmatic faith in technological solutions within the BAUM-driven market institutions. The leading academic institutions across the world are belatedly asking the question: What exactly has happened and is happening in the global higher education system due to the CVP 2020 [2-6]? Notice how they are failing to ask most crucial questions: 
1. Why and where across the globe did the CVP 2020 originate and break out? How did it happen [2-6]?

2. How did it cripple the world's institutions, their normal functionality and delivery systems?

3. What are the anthropogenic trajectories of the CVP 2020, if any [2-6]?

Addressing humanity itself, as this last question does, opens a significant line of inquiry into the possible past blunders and heinous collective crimes that have been committed against nature for which humanity itself may be held accountable. Unless we answer the questions 1-3 and turn a scrutinizing gaze on our international institutions, notably the WHO, experts will repeat the old mistake of racing to offer hasty answers and ad hoc measures. On the contrary, what we need to do is to undertake the urgently needed redesigning of the delivery systems in the academic and healthcare institutions. For the virology research laboratories across the world, and in Wuhan, China, in particular, this means nothing less than a thoroughgoing overhaul of safety standards under international supervision. However, is the WHO competent enough to ensure this? This question calls for a detailed discussion. For limitations of space, this task must be postponed for another occasion.

The world as we knew it before the CVP 2020 broke out [2-6] was proudly built upon the evil destruction of nature by ADNE. Until now, humanity's survival has mainly been due to the smartness that we could owe to TWC. TWC is best represented by the local, regional and international/global institutions including the academic institutions, among them schools, colleges, universities, research institutes, as well as the industrial chains of production of goods and services. Additionally, at a much deeper level, all the languages that have ever existed, or that exist now, are treasures of TWC [60]. In other words:

"There is now a wealth of evidence showing how language structure emerges through a process of cultural evolution. However, the wider implications of this work have received insufficient attention. In particular, our growing knowledge of the role played by cultural evolution has significant implications for what we should expect biological evolution to account for in the emergence of language. Rather than accounting for language structure itself, the key task for biological evolution lies in accounting for the foundational traits that make a process of structure-creating cultural evolution possible. We identified two key traits: the central role of learning in the transmission of the communication system; and the ability to recognize the communicative intent of a signal or action." [38,39] (p. 23)

\section{Epilogue}

Let me now briefly conclude the foregoing discussions as follows. In Sections 1-4 above, I argued for the following view. Given the current global challenges, notably the climate change crisis and the coronavirus pandemic [2-6] among them, never before has it become more urgent for humanity to make a transition to a wisdom inquiry-driven and newly built world. Such a transition entails wide-ranging institutional transformations so that the academic institutions of learning, research laboratories, healthcare institutes, and international institutions can promote wisdom and solve the problems of human wellbeing, instead of focusing on knowledge and technological prowess. Arguing from the perspective of environmental realism [27,28,30-34,40-44,47,54,55,59,61-65], I have shown how human well-being interests and nature's well-being are inseparably connected, making this task even more challenging and urgent.

Accordingly, I proposed how wisdom in the context of institutional change is to be understood as a resource or, better, a highly valuable wis-design-resource, with which we can build and rebuild better and wiser institutions. This huge task must address diverse problem situations in diverse fields of human activity, viz., academic institutions of learning, education, the economy, medicine, healthcare, virology research, international health regulations for G-O-F experiments, the environment, industry, UNSDGs 2030, and the free market. If we want to improve and transform our world into a better and wiser 
world, as if re-building a ship sailing across the stormy seas, then we must look for more and more wisdom in the types of institutions with which we must rebuild our world. In summary, put very simply, I have defended the following thesis: As and when the academic institutions of learning, among a whole variety of the above-mentioned institutions, and the societies / governments that run them, fail, we should let the better and wiser designs, i.e., wis-designs, prevail.

Funding: This research received no external funding.

Institutional Review Board Statement: Not applicable.

Informed Consent Statement: Not applicable.

Data Availability Statement: Not applicable.

Acknowledgments: The author dedicates this article to the Memory of his brother Dwarika Nath Pandita (27 April 1927-4 May 2021) and Mahadev Ram Pandit, Dhanai (Schobha Pandit) Razdan, Devcki (Vischen) Razdan and Durga (Dhar) Rischi; and to all the women, men and children across the globe who became the victims of the Coronavirus Pandemic 2020 and who gave their lives, leaving behind the anonymously trailing footprints (anonym nachlaufende Fußspuren) for the future of humanity. For critiquing an earlier draft of the article, the author thanks Sandra Klevansky and Georg Wolschin from the University of Heidelberg, Sunil Nautiyal, Centre for Ecological Economics \& Natural Resources, Isec: Bangalore; Matthias Kiesselbach, DFG Office India; Vijay Kumar Kaul, Delhi University; Shailendra Kumar, Govt. of India, New Delhi, Rajinder Kumar Kaul, New Delhi, and Lisa Osbeck, University of West Georgia. He thanks Nicholas Maxwell for reading, critiquing and suggesting improvements on several aspects of the article, and for inviting it for the Special Issue of Philosophies [devoted to Saving Humanity from Disaster: Nicholas Maxwell, Guest Ed. (2021), "From the Acquisition of Knowledge to the Promotion of Wisdom"]. The author is thankful to the anonymous referees for reading and commenting on the manuscript; and to Elaine Griffiths, University of Heidelberg, for reading and editing the manuscript.

Conflicts of Interest: The author declares no conflict of interest/competing interests.

\section{Abbreviations}

CCE climate change emergency

UNSDGs 2030 UN sustainable development goals 2030

UNUDHR United Nations' universal declaration of human rights adopted and proclaimed

1948

GDP

by UN General Assembly Resolution 217 A (III) of 10 December 1948

A measure of the economic life of citizens, including their access to goods and services, i.e., a tool that measures the level of production of goods and services in an economy, the income generated by them, and also how much is consumed, saved and invested

G-O-F experi- Gain-of-Function experiments that aim at enhancing the strength of a virus to ments better study its effects on hosts, thereby making a virus more dangerous, as compared to those experiments that research how the virus might transmit across species

WIV Wuhan Institute of Virology

CVP $2020 \quad$ Coronavirus pandemic 2020

CCP Chinese Communist Party

WHO World Health Organization, with 194 countries as its members, set up as an agency of the UNO in 1948, aims for universal health coverage, improvement of health and well-being, and the prevention of health emergencies/crises, globally

GOFVRIs Gain-of-Function Virology Research Institutes

IHRs Iternational Health Regulations 2005

TWC Traditional wisdom of culture as represented by the knowledge inquiry-driven, scientific and academic institutions of learning, and by the knowledge resources of natural languages, artefacts, norms, social institutions such as family traditions, works of art, education, numbers, medicine and healthcare culture of wisdom inquiry 


\section{References}

1. Moore, G.E. Principia Ethica; [First paperback ed. 1959]; The University Press: Cambridge, UK, 1903.

2. Hatta, N. How China blocked WHO and Chinese scientists early in Corona Virus outbreak: Despite publicly lauding China, WHO officials complained privately that the country wasn't sharing vital information. In Pool via Reuters File; The Associated Press: New York, NY, USA, 2020.

3. Davidson, H. First Covid-19 Case Happened in November 2019, China Government Records Show-Report. Available online: https: / / www.theguardian.com/world/2020/mar/13/first-covid-19-case-happened-in-november-china-governmentrecords-show-report (accessed on 13 March 2020).

4. Redfern, H. How Did Coronavirus Start and Where Did It Come From? Was It Really Wuhan's Animal Market? Available online: https:/ / www.theguardian.com/world/2020/apr/28/how-did-the-coronavirus-start-where-did-it-come-from-howdid-it-spread-humans-was-it-really-bats-pangolins-wuhan-animal-market (accessed on 28 April 2020).

5. McMullen, J. Covid-19: Five Days That Shaped the Outbreak. Available online: https://www.bbc.com/news/world-55756452 (accessed on 26 January 2021).

6. Pandit, S.; Taubert, J. Welche Auswirkungen Hatte die Corona-Pandemie und Besonders der Erste Lockdown im Frühjahr 2020 auf die Menschen Rund um Das AMG? Available online: https://www.amg-trier.de/amg/schule/magazin/ (accessed on 18 October 2021).

7. AL-Hmoud, N. Comments. In Proceedings of the Gain-of-Function-The Second Symposium, National Academies of Sciences, Engineering, and Medicine, Washington, DC, USA, 11 March 2016. Available online: https://www.youtube.com/playlist?list= PLuTGMA3A_-175RgOxOwYyy_-1A6gBHZTYN (accessed on 15 January 2021).

8. Evans, N.G. Ethical and Philosophical Considerations for Gain-of-Function Policy: The Importance of Alternate Experiments. Front. Bioeng. Biotechnol. 2018, 6, 11. [CrossRef] [PubMed]

9. Evans, N.G. Great expectations-Ethics, avian flu and the value of progress. J. Med. Ethics 2013, 39, 209-213. [CrossRef] [PubMed]

10. Evans, N.G. Valuing knowledge: A reply to the epistemological perspective on the value of gain-of-function experiments. MBio 2014, 5, e01993-14. [CrossRef] [PubMed]

11. Evans, N.G.; Lipsitch, M.; Levinson, M. The ethics of biosafety considerations in gain-of-function research resulting in the creation of potential pandemic pathogens. J. Med. Ethics 2015, 41, 901-908. [CrossRef]

12. Evans, N.G.; Selgelid, M.J. Biosecurity and open-source biology: The promise and peril of distributed synthetic biological technologies. Sci. Eng. Ethics 2014, 21, 1065-1083. [CrossRef] [PubMed]

13. Maxwell, N. From Knowledge to Wisdom: A Revolution in the Aims and Methods of Science; Basil Blackwell: Oxford, UK, 1984.

14. Maxwell, N. Is Science Neurotic? Imperial College Press: London, UK, 2004.

15. Maxwell, N. What Is Wrong with Science? 2nd ed.; (First published by Bran's Head Books); Pentire: London, UK, 1976.

16. Maxwell, N. How Can Life of Value Best Flourish in the Real World. In Science and the Pursuit of Wisdom: Studies in the Philosophy of Nicholas Maxwell; McHenry, L., Ed.; Ontos Verlag: Frankfurt, Germany, 2009; pp. 1-56.

17. Maxwell, N. Are Universities Undergoing an Intellectual Revolution. Available online: http://philsci-archive.pitt.edu/id/eprint/ 4706 (accessed on 18 October 2021).

18. Maxwell, N. Reply to Comments on Science and the Putsuit of Wisdom. Philosophia 2010, 38, 667-690. [CrossRef]

19. Maxwell, N. Arguing for Wisdom in the University: An Intellectual Autobiography. Philosophia 2012, 40, 663-704. [CrossRef]

20. Maxwell, N. In Praise of Natural Philosophy: A Revolution for Thought and Life. Philosophia 2012, 40, 705-715. [CrossRef]

21. Maxwell, N. Global Philosophy: What Philosophy Ought to Be; Imprint Academic: Exeter, UK, 2014.

22. Maxwell, N. Popper's Paradoxical Pursuit of Natural Philosophy. In The Cambridge Companion to Popper; Shearmur, J., Stokes, G., Eds.; Cambridge University Press: Cambridge, UK, 2019; Chapter 7; pp. 170-207.

23. Maxwell, N. Two Great Problems of Learning: Science and Civilization; Springer; Berlin, Germany, 2016.

24. Maxwell, N. In Praise of Natural Philosophy; McGill-Queen's University Press: Montreal, QC, Canada, 2017.

25. Maxwell, N. Science and Enlightenment: Two Great Problems of Learning; Springer Nature: Cham, Switzerland, 2019; ISBN 9783030134198.

26. Maxwell, N. From Knowledge to Wisdom. Available online: https:/ /www.ucl.ac.uk/from-knowledge-to-wisdom/ (accessed on 18 October 2021).

27. Pandit, G.L. Ecosystem-Resilience: A long journey to nature policy. In Knowledge Systems of Societies for Adaptation and Mitigation of Impacts of Climate Change (Environmental Science and Engineering); Nautiyal, S., Rao, K.S., Kaechele, H., Raju, K.V., Schaldach, R., Eds.; Springer: Berlin/Heidelberg, Germany, 2013; pp. 57-86.

28. Pandit, G.L. Knowledge-Based Climate Economy: Integrated Sciences, Accelerated Convergence and Knowledge Resources Dynamics. In Climate Change Challenge (3C) and Social-Economic-Ecological Interface-Building; Nautiyal, S., Ruediger, S., Raju, K.V., Kaechele, H., Pritchard, B., Rao, K.S., Eds.; Springer International Publishing: Cham, Switzerland, 2016; pp. 133-160. [CrossRef]

29. Pandit, G.L. How Simple is it for Science to Acquire Wisdom According to its Choicest Aims? Philosophia 2010, 38, 649-666, (A Special No. of Philosophical Quarterly of Israel). [CrossRef]

30. Pandit, G.L. Rethinking Nature and Environment: Against Technological Totalitarianism. In Environment, Economy and Society: Lessons and Imperatives; Dhankar, R.S., Ed.; Readworthy Publications: New Delhi, India, 2017; pp. 1-63.

31. Pandit, G.L. Children's Education, Institutions of Learning, Technology and Wisdom Inquiry: Global Challenges and Methodological Perspectives. Philosophia 2020, 48, 1117-1145, (Philosophical Quarterly of Israel). [CrossRef] 
32. Pandit, G.L. Scenarios of Global Interconnectedness: Turning Leibniz's Research Programme Around. In Proceedings of the Akten des X. Internationalen Leibniz-Kongresses, Hannover, Germany, 18-23 July 2016; 6 Baende (6 Vols.). Li, W., Ed.; Olms: Hildesheim, Germany; Zürich, Switzerland; New York, NY, USA, 2016; Volume 1, pp. 159-174.

33. Pandit, G.L. Ethics in Public Domain: Biomedical Research and Beyond. In Bio-Nano-Geo Sciences: The Future Challenge; Srivastava, A., Roy, I., Eds.; Anne Books: New Delhi, India; Chennai, India; Mumbai, India, 2009; pp. 187-208. Available online: www. science-cooperation.org/www.science-circle.org (accessed on 18 October 2021).

34. Pandit, G.L. State of Collective Crimes beyond the South Asian Political Ritual Dynamics. World Aff. J. Int. 2010, 14, 164-176.

35. Pandit, G.L. Rethinking Science-Studies with a Return to Natural Philosophy. In Friends of Wisdom Newsletter, 1st ed.; UCL: London, UK, 2007; pp. 28-32.

36. Pandit, G.L. Universities with a Room for Wisdom Inquiry. In Friends of Wisdom Newsletter; UCL: London, UK, 2008 ; pp. 4-9.

37. Pandit, G.L. Aim Oriented Empiricism: How We Might Improve the Aims and Methods of Science, Making It More Rational, Responsible and Far Reaching. Available online: https://www.ucl.ac.uk/drupal/site_friends-of-wisdom/sites/friends-ofwisdom/files/newsletter06.pdf (accessed on 18 October 2021).

38. Thomas, J.; Kirby, S. Self-domestication and the evolution of language. Biol. Philos. 2018, 33, 9. [CrossRef] [PubMed]

39. Thompson, B.; Kirby, S.; Smith, K. Culture shapes the evolution of cognition. Proc. Natl. Acad. Sci. USA 2016, 113, 4530-4535. [CrossRef] [PubMed]

40. Pandit, G.L. Where the World makes its Home in a Single Nest: Wisdom of Culture-Driven Knowledge Environments. In Proceedings of the Humboldt Colloquium: "Germany and India-Partners in Education and Research", Bangaluru, India, 23-25 November 2017.

41. Pandit, G.L. Rebuilding Democracy, Rethinking Education. In Democracy and Education: Collected Perspectives; Byczkiewicz, V., Ed.; Trebol Press: Los Angeles, CA, USA, 2014; pp. 161-222.

42. Pandit, G.L. Ethical Tasks of Media Advocacy in the 21st Century. Available online: http://wab.uib.no/ojs/index.php/agoraalws/article/view/2655/3033 (accessed on 18 October 2021).

43. Pandit, G.L. Von der Oekologie des Bewusstseins zum Umweltrealismus-Die Wiederentdeckung menschlicher und nichtmenschlicdher Interessenssphaeren. In Wiener Vorlesungen Band 41; Picus Verlag: Wien, Austria, 1995.

44. Pandit, G.L. Emergence of the Human Interests Studies: The Environmental Dimension. In Proceedings of the Conference Problems of Individual Emergence, Amsterdam, The Netherlands, 16-20 April 2001; (Special Issue: Systemica Journal of the Dutch Systems Group Vol. 14 (2007: 295-312)). de Zeeuw, G., Vahl, M., Mennuti, E., Eds.; Lincoln Research Centre: Lincoln, UK, 2007.

45. Tagore, R. The Centre of Indian Culture; Visva-Bharati: Culcutta, West Bengal, India, 1919; pp. 1-44.

46. Kareiva, P.; Watts, S.; McDonald, R.; Boucher, T. Domesticated Nature: Shaping Landscapes and Ecosystems for Human Welfare. Science 2007, 316, 1866-1869. [CrossRef] [PubMed]

47. Pandit, G.L. A Science of Universal Interconnectedness: Rationality of Wisdom Inquiry. In Proceedings of the IX. International Leibniz-Kongress: Nature and Subject, Nachtragsband, Hannover, Germany, 26 September-1 October 2011; von Herbert Breger, H., Herbst, J., Erdner, S., Eds.; Druckerei Hartmann GmbH: Hannover, Germany, 2012; pp. 214-225.

48. Popper, K.R. The Rationality of Scientific Revolutions. In Problems of Scientific Revolution; Harre, R., Ed.; Oxford University Press: Oxford, UK, 1975; pp. 72-101.

49. Pandit, G.L. The Structure and Growth of Scientific Knowledge-A Study in the Methodology of Epistemic Appraisal; Boston Studies in the Philosophy of Science; Cohen, R.S., Wartofsky, M.W., Eds.; Springer: Dordrecht, The Netherlands; Boston, MA, USA; London, UK, 1983; Volume 73, p. 231.

50. Pandit, G.L. Methodological Variance: Essays in Epistemological Ontology and the Methodolohy of Science; Boston Studies in the Philosophy of Science; Springer: Dordrecht, The Netherlands; Boston, MA, USA; London, UK, 1991; Volume 131, p. 422.

51. Popper, K.R. Logik der Forschung, Wien. (English Translation, Logic of Scientific Discovery); Hutchinson: London, UK, 1959; Basic Books: New York, NY, USA. First German Ed. Vienna 1934.

52. Popper, K.R. Conjectures and Refutations; Routledge \& Kegan Paul: London, UK, 1963.

53. Popper, K.R. Objective Knowledge: An Evolutionary Approach; Clarendon Press: Oxford, UK, 1972.

54. Pandit, G.L. Normative Methodology of Science: Karl Popper (1902-1994) and Hans Albert. Giuseppe Franco (Hrsg.). In Begegnungen mit Hans Albert_Eine Hommage; Springer Fachmedien Wiesbaden GmbH: Wiesbaden, Germany, 2019 ; pp. 259-268. [CrossRef]

55. Pandit, G.L. Leibniz and the Changing Images of Universal Interconnectedness. In VII. Internationaler Leibniz-Kongress "NIHIL SINE RATIONE—Mensch, Natur und Technik im Wirken von G. W. Leibniz"; Vortraege 2; Poser, H., Ed.; Teil. Technische Universitaet: Berlin, Germany, 2001; pp. 942-947.

56. Leibniz, G.W. Die philosophischen Schriften von Gottfried Wilhelm Leibniz; Gerhardt, C.I., Ed.; Weidmann: Berlin, Germany, 1875-1890; Reprint Georg Olms: Hildesheim, Germany, 1978; VII 316-317, pp. 84-85.

57. Lovejoy, A.O. The Great Chain of Being; Harvard University Press: Cambridge, MA, USA, 1936.

58. Bohm, D. Wholeness and the Implicate Order; (First Published 1980); ARK Paperbacks: London, UK; New York, NY, USA, 1983; p. 175.

59. Pandit, G.L. Paradoxes of Progress: How Can Humanity Improve Environmental Thinking and Environmental Action? Politics Life Sci. 1999, 18, 241-242. [CrossRef]

60. Bernstorff, D.; von Welck, H. Exile as Challenge: The Tibetan Diaspora; Orient Longman: New Dehi, India, 2004 ; p. 488. 
61. Pandit, G.L. World's Refugees: What Humanity Owes to Them. World Aff. J. Int. 2005, 9, 148-156.

62. Hayes, C. Fallibilism, Democracy and the Market: The Meta-Theoretical Foundations of Popper's Political Philosophy; University Press of America, Inc.: Lanham, MD, USA; New York, NY, USA; Oxford, UK, 2001.

63. Pandit, G.L. Participate and Reconnect: The Problem of Improving the Human Condition. In Proceedings of the International Conference Problems of Participation and Connection, Amsterdam, The Netherlands, 5-9 April 1999; A Special Issue of Systemica 13 (2001, 337-341), the Journal of the Dutch Systems Group. de Zeeuw, G., Vahl, M., Mennuti, E., Eds.; Lincoln Research Centre: Lincoln, UK, 2001.

64. Pandit, G.L. Freudian Frontiers of Psychoanalytic Theory and Therapy: A Case of Improvement of Scientific Knowledge? J. Constr. Psychol. 2020, 1-27. [CrossRef]

65. Pandit, G.L. Exclusion and Uprootment in Kashmir: From a Political Tragedy to an Ecological Catastrophe. World Aff. J. Int. 2006, 10, 152-171. 